\title{
Hybrid Power Pack: Hybrid Powertrain for City Cars
}

\author{
Fabio Cignini' ${ }^{1}$, Sergio De Domenico ${ }^{1}$, Leone Martellucci' ${ }^{1}$, Roberto Capata ${ }^{2}$ \\ ${ }^{1}$ Department of CTL, Sapienza University, Rome, Italy \\ ${ }^{2}$ Department of Mechanical \& Aerospace Engineering, Sapienza University, Rome, Italy \\ Email: fcignini@gmail.com, sergiodedomenico.uni@gmail.com, leone.martellucci@uniroma1.it, \\ roberto.capata@uniroma1.it
}

Received 12 August 2014; revised 8 September 2014; accepted 2 October 2014

Copyright (C) 2014 by authors and Scientific Research Publishing Inc.

This work is licensed under the Creative Commons Attribution International License (CC BY). http://creativecommons.org/licenses/by/4.0/

c) (i) Open Access

\begin{abstract}
This paper presents a novel concept, the Hybrid Power Pack (HPP), which consists of a hybridization kit for transforming small city cars, powered by an original diesel engine, into a parallel hybrid vehicle. The study was jointly conducted by the University of Rome "Sapienza" and the Enea Casaccia research center. The idea is to design a hybrid powertrain that can be installed in a typical microcar, which means that all systems and components will be influenced by the limited space available in the motor compartment of the vehicle. In this paper the details of the mechanical and electrical realization of the powertrain will be discussed and the simulation of a small city car equipped with HPP will be presented and the results discussed and analyzed. The hybrid system also includes the battery pack which is composed of twenty-four Li-ion cells made by EIG, connected in series. The storage system is controlled as regards the voltage and temperature by a Battery Management System (BMS). All the above components are connected and managed by a control unit. The HPP presented in this paper obtains a reduction in fuel consumption higher than $\mathbf{2 0 \%}$. The solution presented with the HPP with its management strategy and the addition of the "plug-in function" makes the hybrid vehicle suitable in terms of performance and consumption in every driving conditions. The ideal strategy behind the "plug-in function" could represent a guideline for further achievements and experimentations, because it offers a simple hardware layout and a real reduction in fuel consumption.
\end{abstract}

\section{Keywords}

Hybrid, Vehicle, City Car, Battery, Energy, Sustainability

\section{Introduction}

Today, most governments in the world have declared sustainable development as one of their main goals. This

How to cite this paper: Cignini, F., De Domenico, S., Martellucci, L. and Capata, R. (2014) Hybrid Power Pack: Hybrid Powertrain for City Cars. Journal of Transportation Technologies, 4, 315-326. http://dx.doi.org/10.4236/jtts.2014.44028 
implies, among other things, the protection of the environment and thus the reduction in the use of non-renewable fossil energy sources. Transportation is responsible for $57 \%$ of the world's petrol consumption, of which $80 \%$ concerns road transportation. In the European Union [1], where there is the largest concentration of vehicles in the world, these considerations have led to:

- The issuing of emission regulations for gasoline and diesel-fuelled vehicles: starting from January 1 st 2011. All new registered vehicles must respect the EURO 5 standards which will be updated to a substantially more restrictive EURO 6 from September 1st 2015.

- The delivery of Economic incentives for buying innovative vehicles, as the Hybrid Electric Vehicles (HEVs) and the Electric Vehicles (EVs).

- The Italian Government, according to the "Italian Directive 83/2012", promotes, in 2013, the production and the commercialization of ecological vehicles. The current automotive market offers many different models and solutions, for EVs and HEVs. However, regarding small vehicles (from $4 \mathrm{~kW}$ to $15 \mathrm{~kW}$ ) there are no hybrid models available on the market.

This paper presents a novel concept, the Hybrid Power Pack (HPP), which consists of a hybridization kit for converting small microcars, powered by a diesel engine, into a parallel hybrid vehicle. The study was jointly conducted by the University of Rome "Sapienza" and the "Enea-Casaccia" research center.

\section{Hybrid Powertrain Concept and Configuration}

The starting idea is to design a hybrid power train that can be installed in a typical microcar, which means that all systems and components will be influenced by the limited available space in the motor compartment of the vehicle [2]-[4]. The engine block chosen for this project is a commercial product by the Italian engine company Lombardini. It consists of an internal combustion Diesel engine (ICE), equipped with a CVT transmission system of the type usually mounted on microcars. The engine is managed by an Electronic Control Unit (ECU) which controls all the engine's operational parameters (ignition timing, etc.). Table 1 reports the main parameters of this diesel engine.

The hybrid power train has been realized by connecting the ICE engine to an electric motor. The connection between the two engines is obtained by means of a steel flange (Figure 1).

\begin{tabular}{cccc} 
Table 1. ICE specifications. & & \\
\hline Type & Diesel 4T, Common Rail & Max Power & $8.5 \mathrm{~kW}$ \\
Cylinders & 2 & Max Revolution Speed & $4400 \mathrm{RPM}$ \\
Displacement & $440 \mathrm{~cm}^{3}-$ Bore \& Stroke $68 \times 60.6 \mathrm{~mm}$ & Max Torque @ 2000 RPM & $21 \mathrm{Nm}$ \\
Weight & $48.5 \mathrm{~kg}$ & Max Fuel Specific Consumption & $320 \mathrm{~g} / \mathrm{kWh}$ \\
\hline
\end{tabular}

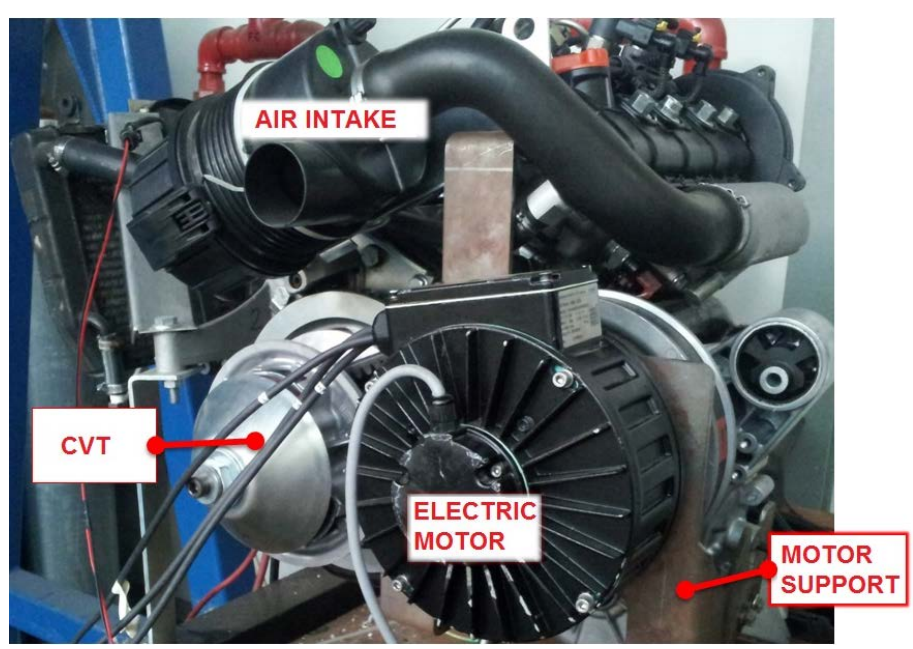

Figure 1. Engine with CVT transmission. 
The electric motor chosen is a PMS 100 by Perm Motor: this choice has been dictated by several design requirements and constraints:

- Capability to deliver the same torque as the diesel engine.

- Maximum rpm not to exceed 5000.

- Light weight packaging (total weigh of the electric motor less than $7 \mathrm{~kg}$ ).

In Table 2 are listed the main specifications of the electric motor.

To control the electric motor, an inverter is used [5]. The hybrid system also includes the battery pack [6] which is composed of twenty-four Li-ion cells (Table 3), connected in series. Each cell has a nominal voltage of $3.6 \mathrm{~V}$ and a capacity of $20 \mathrm{Ah}$. Such a Li-ion cell [7] can be overcharged at $1.5 \mathrm{C}$ and discharge at $5 \mathrm{C}$. The storage system voltage and temperature is controlled by a Battery Management System (BMS) [8] [9].

All the above components are connected and managed by a control unit. The final scheme of the hybrid power train is shown in Figure 2. The aim of the present work is the optimization of the code.

\section{System Simulation Model}

To virtually simulate the hybrid powertrain the Amesim software has been used. This simulation software allows simulating of complex automotive systems.

To create the HPP model [10] in the software, much information about each component is needed. For example, the hybrid vehicle's control unit must contain in its memory all the operational parameters for both engines (ICE and electric motor) to function correctly. To identify and represent the operating parameters of the ICE engine, the specifications and data were supplied by the factory, as well as for the electric motor. For example, in Figure 3 and Figure 4, is presented the consumption trend of the diesel engine. These data has been used to create the model, for properly simulating the ICE behavior.

Table 2. PMS 100-Electric motor specifications.

\begin{tabular}{|c|c|c|c|c|c|c|c|c|}
\hline RPM Range & \multicolumn{4}{|c|}{ From 0 to $6000 \mathrm{RPM}$} & \multicolumn{4}{|c|}{ Depending on the windings } \\
\hline Nominal Power & \multicolumn{4}{|c|}{ Up to $3 \mathrm{~kW}$} & \multicolumn{4}{|c|}{ Depending on the RPM and voltage } \\
\hline Torque & \multicolumn{4}{|c|}{$\sim 8 \mathrm{Nm}$} & \multicolumn{4}{|c|}{ For RPM $<1800$} \\
\hline Max Torque & \multicolumn{4}{|c|}{$\sim 24 \mathrm{Nm}$} & \multicolumn{4}{|c|}{ For a max. of $0.5 \mathrm{Sec}$. at RPM $<50$} \\
\hline Weight & \multicolumn{4}{|c|}{$\sim 5,8 \mathrm{KG}$} & \multicolumn{4}{|c|}{ Included encoder's signals } \\
\hline Voltage & \multicolumn{2}{|c|}{$24 \mathrm{~V} \mathrm{DC}$} & \multicolumn{2}{|c|}{$48 \mathrm{~V}$ DC } & \multicolumn{2}{|c|}{$72 \mathrm{~V}$ DC } & \multicolumn{2}{|c|}{ ab $320 \mathrm{~V}$ DC } \\
\hline RPM & Torque [Nm] & Power [kW] & Torque [Nm] & Power $[\mathrm{kW}]$ & Torque [Nm] & Power $[k W]$ & Torque $[\mathbf{N m}]$ & Power $[\mathrm{kW}]$ \\
\hline 1500 & 7.64 & 1.2 & 7.0 & 1.1 & 7.64 & 1.2 & 7.0 & 1.1 \\
\hline 3000 & 4.78 & 1.5 & 7.64 & 2.4 & 7.0 & 2.2 & 6.7 & 2.1 \\
\hline 4500 & - & - & 5.31 & 2.5 & 5.31 & 2.5 & 5.1 & 2.4 \\
\hline 6000 & - & - & 4.30 & 2.7 & 4.14 & 2.7 & 4.78 & 3.0 \\
\hline
\end{tabular}

Table 3. Driving cycles.

\begin{tabular}{ccccc}
\hline Driving Cycle & ECE 15 & "NEDC Modified" & UECC & NYCC \\
\hline Distance [m] & 994.6 & 3954 & 1015 & 1900 \\
Time [s] & 195 & 660 & 150 & 568 \\
Standing Time [\%] & $23 \%$ & $26 \%$ & $35 \%$ & $33 \%$ \\
Braking Time [\%] & $20 \%$ & $22.6 \%$ & $7 \%$ & $22 \%$ \\
Average Speed [m/s] & 5.1 & 5.5 & 6.9 & 3.19 \\
Max Acceleration [m/s $\left.\mathbf{s}^{2}\right]$ & 1.4 & 1.7 & 4 & 3.1 \\
\hline
\end{tabular}




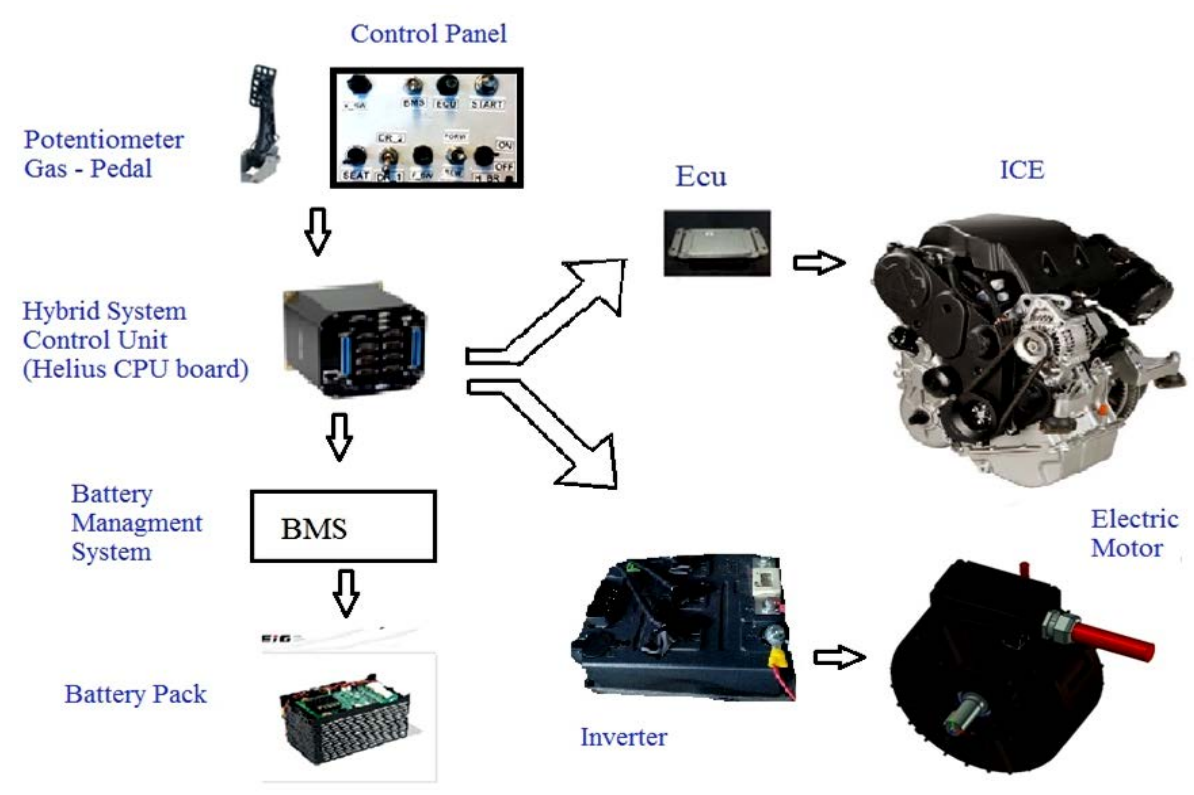

Figure 2. Powertrain layout.

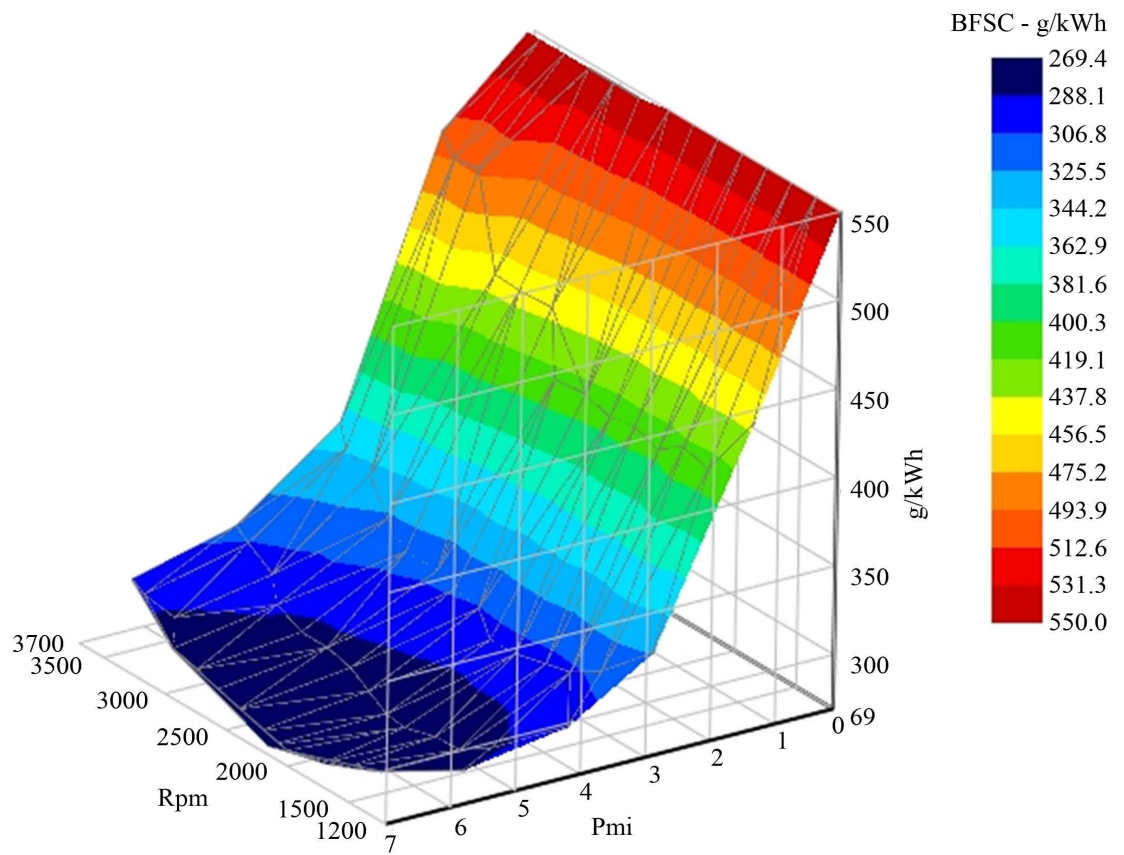

Figure 3. ICE Consumption data (3D graph) provided by factory.

Figure 5 shows the final scheme of the proposed parallel hybrid electric microcar. The model, defined by the simulations, is composed of many different blocks each of which represents a specific component of the hybrid vehicle.

Some of the components have been used to create the model already existed in the software library to compared and to adjusted the configuration studied, in accordance with the design specifications. Those components are, the Internal Combustion Engine, the Engine Control Unit, the Vehicle, the CVT transmission and the Electric Motor. The sub-models named "Regenerative Braking" and "Direct Control Logic" were specifically implemented ex novo: they simulate the control logic of the regenerative braking and the interaction and coupling of the two motors (ICE and electric). 


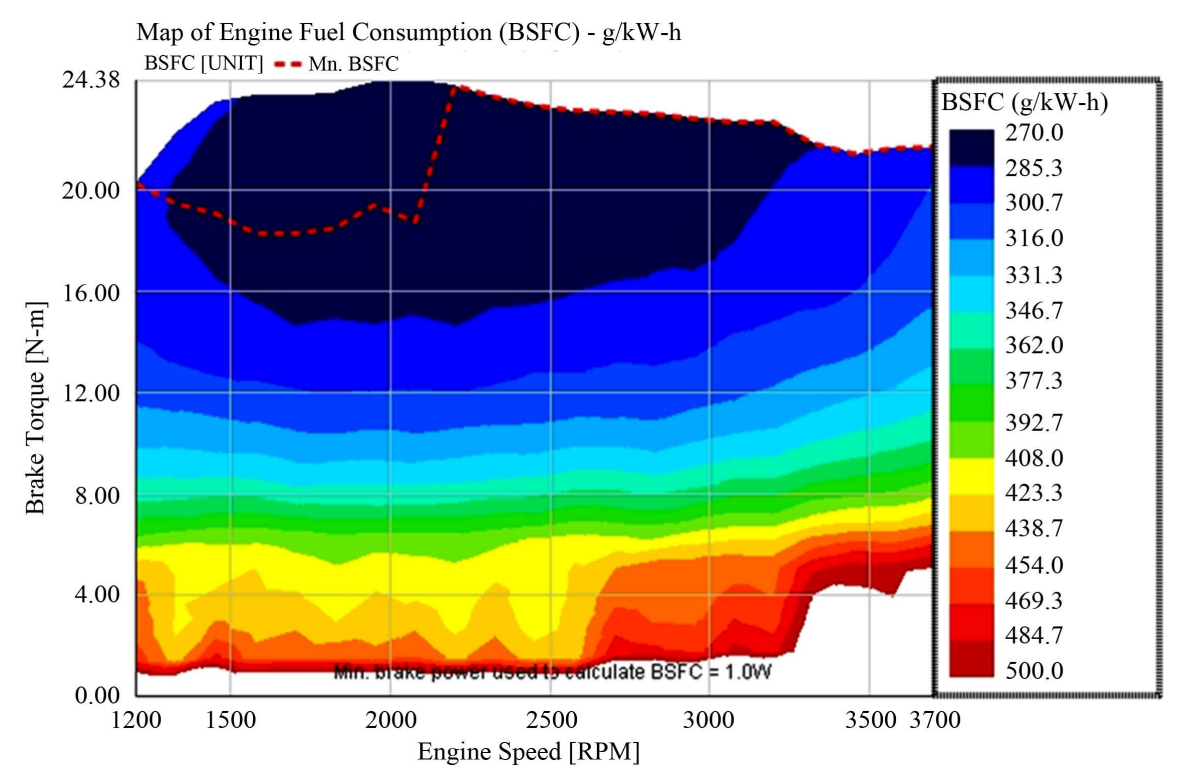

Figure 4. ICE Consumption data (2D graph) provided by factory.

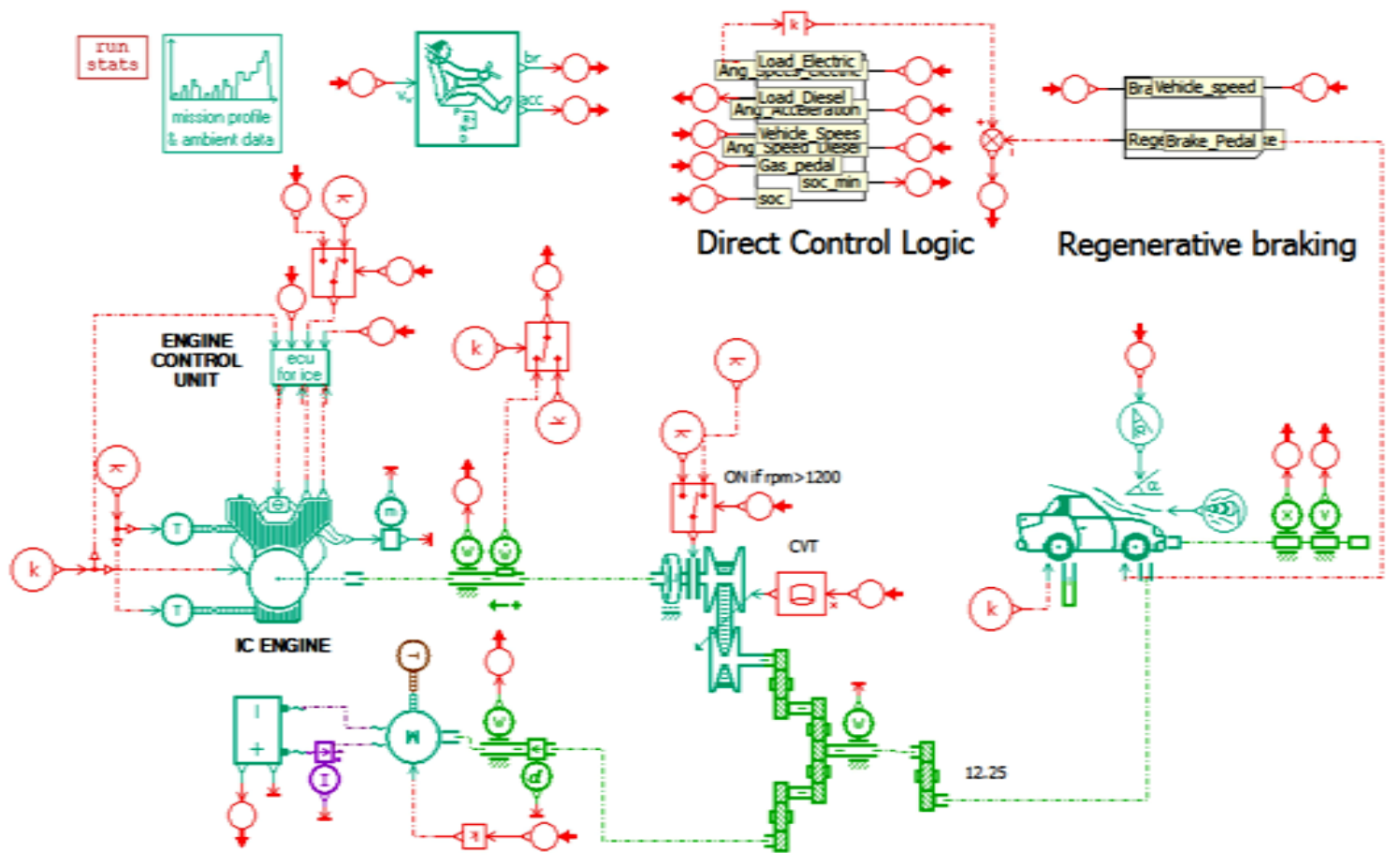

Figure 5. Amesim software model.

Each block, as previously stated, represents a real vehicle component and for this reason they must be set using appropriate parameters.

The most important components/blocks composing the model are:

- Battery block, defined by the voltage and the capacity of the single cell, the number of cells connected in series that compose the rack of the battery pack, etc.

- Mission profile block. It defines the track along which the simulation takes place; it is usually defined by a case-specific table that represents the simulated road conditions imposed on the driver block: speed, slope of the road, etc. 
- Driver block. It represents and simulates the behavior of an actual driver according to the information coming from the driving cycle parameters defined in the mission profile block.

- Start \& Stop controller. It is a switch that turns off the diesel engine when the speed of the simulated vehicle falls below a certain threshold.

- The sub-model block, "Direct Control Logic". It is set and programmed to accept some variables as input and to produce three different signals as output.

- Input: battery state of charge, real vehicle speed, and load imposed by the driver by means of the gas pedal.

- Output: activation signal for the electric motor and ICE (based on the load requested), when SOC $\leq$ SOC_ MINIMUM. The criteria used to generate the output are imposed with specific look up tables based on the input parameters such as: RPM of both engines, the battery state of charge (SOC), the real vehicle speed, etc.

- A sub-model block that receives all brake signals generated by the driver block, and manages the braking:

- If the generated brake signal (normalized between 0 and 1) has a value close to 1 (intense braking or fast braking), the braking will be made by the mechanical brake of the vehicle and there will be no regenerative braking effect.

- If the brake signal is close to 0 (mild braking or slow braking), the braking action will be enforced regeneratively by the electric motor. That is, the electric motor will offer a negative torque (in the direction contrary to that of the ICE torque) to slow down the vehicle and at the same time, working as a generator, it will recover a part of the ICE kinetic energy lost during the deceleration to produce electricity to recharge the batteries.

For the European Union, the evaluation criteria for standardized consumption and emission testing are presented in document [1]. However, the HPP system presented in this paper represents an innovation in the automotive sector, therefore it has been simulated not only according with the EU standards cycle (the utilized cycles are shown in Table 3) but also with a full performances cycle derived from real mission data.All the simulations lead to determine the fuel consumption of the proposed hybrid system.

The following driving cycles have been used in the simulations [11]:

- The "NEDC modified" is a cycle inspired by the NEDC cycle which is required for the certification of many types of vehicles in the EU. The "NEDC modified" cycle is different from the standard NEDC cycle because of the reduction in speed adopted in the urban and extra-urban sections of the cycle. This kind of testing cycle is, however, far from a real urban driving situation, because the maximum vehicle acceleration is set at around $1.7 \mathrm{~m} / \mathrm{s}^{2}$ which is not realistic. In any case, it is used by every car manufacturer, and thus it must be simulated to obtain comparison parameters.

- The "ECE 15" is a typical cycle imposed by EU standards. It's composed of three very mild driving sections.

- The "UDR1/ENEA Custom Cycle (UECC)" is a cycle created, ad hoc, to test the HPP. The philosophy is to test the vehicle at its maximum acceleration and deceleration, for determining the maximum load conditions and the maximum current of charge and discharge, which will be tested as well.

- The "NYCC" simulates a real urban drive, but it is conceived for vehicles that weigh more than 1 ton. Even considering this restriction, this cycle is very useful for simulations due to its realistic nature.

Each driving cycle determines specific fuel consumption related to its characteristics (speed, slope, braking time, etc.). The main purpose of the proposed hybrid control system is to manage the load demand requested by the driver between the ICE and the electric motor.

The consequences of having such control over the two motors are the reduction of ICE fuel consumption and the increase of battery package lifetime. These savings will occur for every driving cycle because, depending on the driving conditions, only the engine that has the best performance will be put into function by the hybrid system.

\section{Simulation Results}

The main purpose of the simulations is to optimize the parameters (maps) governing the ICE and the electric motor, to obtain the best results in terms of power output and fuel consumption for every possible driving cycle. An important output obtained from the simulations is the torque curves of the two motors. These curves show how the motors behave during different driving cycle conditions.

The torque, the engine speed, the state of charge of the battery and the request of load in percentage are all fundamental parameters to create and fit the maps that control the two motors.

Once all the results are obtained from simulations, they are analyzed and used to create the control maps. This 
optimized code will be then translated in Simulink language and loaded, into the unit hardware. Each of the driving cycles were run in loop thus to consider three different lengths per cycle: $50 \mathrm{~km}, 100 \mathrm{~km}$ and $200 \mathrm{~km}$. For simplicity, in this paper are reported only some significant examples of the obtained results. Figure 6 shows the results for the ECE 15 driving cycle. The red curve represents the vehicle speed $(\mathrm{m} / \mathrm{s})$ during the cycle. The green and the blue curves represent, respectively, the electric motor torque and the ICE torque delivered during the cycle. As can be seen in the figure below, the electric motor mainly operates during the acceleration and deceleration phases.

During the decelerations the electric motor opposing a negative torque, and operates as a generator. The ICE supplies power with a gradual increase of torque, without sharp variations, and when the vehicle needs to decrease speed by braking, both motors produce negative torque.

As previously described the electric motor recovers the energy (regenerative brake), when the braking conditions are satisfied. At high speed, the request of power is supplied by the ICE.

In Figure 7, the NYCC cycle is shown and the above explained effects are visible. Those effects are much more visible in a NYCC then in an ECE, because the NYCC driving cycle is very close to real driving conditions.

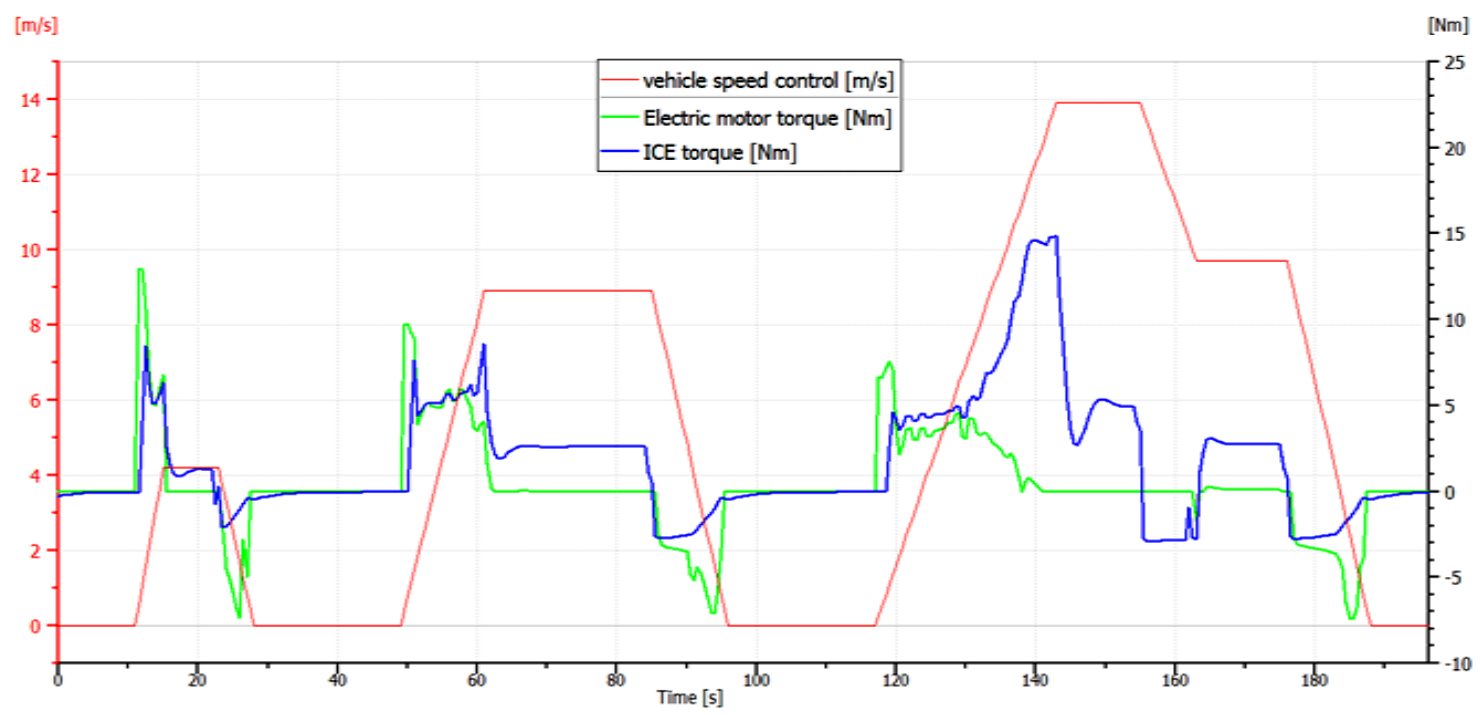

Figure 6. ECE 15 mode cycle.

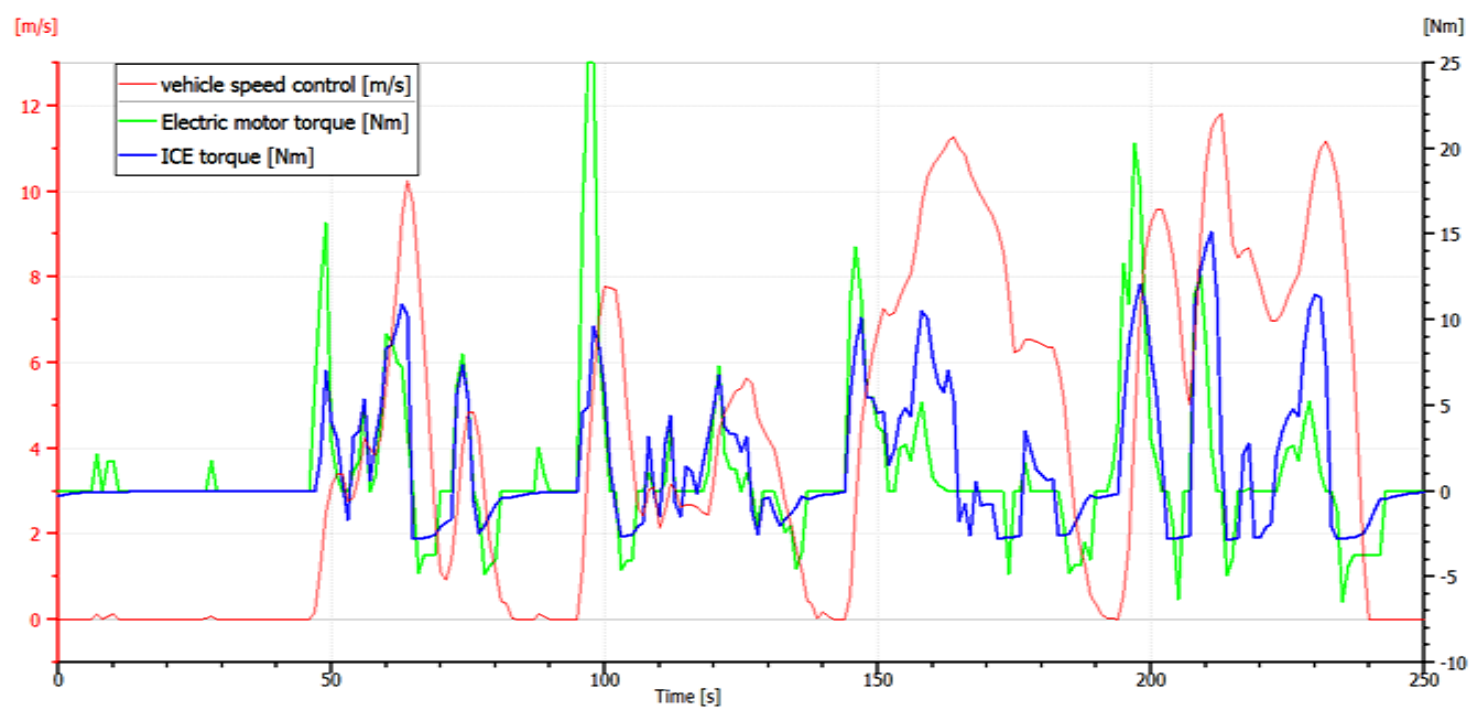

Figure 7. NYCC mode cycle. 
To enlighten the advantages of having a hybrid power train instead of a single diesel ICE, especially for micro cars, comparative simulations have been carried out. Utilizing the same model previously described, and the same testing cycle, first, the diesel engine performances have been simulated (removing from the existing model the blocks regarding the HEV). Afterwards, only the electric motor system has been simulated (removing from the existing model the blocks regarding the ICE) and both cases were then compared with the HPP case (Table 4).

The symbol "*" next to some values in the above tables indicates those cases when the battery SOC reaches the lower limit, and the warning is activated. Warning condition as shown in Figure 7 implies that the vehicle is powered only by the ICE engine until the value of battery state of charge is again over its lower value and it can supply power to the electric motor. These conditions have been detected in 4 cases:

- ECE $10-15$, during the $200 \mathrm{~km}$ cycle after the first $136 \mathrm{~km}$.

- UECC, during the $200 \mathrm{~km}$ cycle after the first $121 \mathrm{~km}$.

- NYCC, during the $100 \mathrm{~km}$ and $200 \mathrm{~km}$ cycle after the first $66 \mathrm{~km}$.

- In the ECE 10 cycle instead the vehicle can run $245 \mathrm{~km}$ before the battery SOC reaches its lower limit.

In Table 5 there is the results obtained from the previous presented simulations are compared, to define the fuel consumption and the value of the endurance until the warning condition occurs.

It can be noticed that in all simulations the Start and Stop controller. Typically, in every simulated driving cycle, the $20 \%$ to $30 \%$ of the total cycle time is occupied by a stop sequence. Traditionally, during these phases the ICE operates at idle causing inevitable fuel consumption. Turning off the engine when the vehicle stops can reduce considerably the fuel consumption. It has been estimated, if the engine is turned off in the stop phases (considering an idle consumption of $0.2 \mathrm{~kg} / \mathrm{h}$ of diesel fuel for the engine) a reduction in consumption of $10 \%$ for an ECE 15 driving cycle, and a reduction of $18 \%$ for the NYCC ones.

The battery state of charge is closely linked with the hybrid vehicle consumptions. In fact, excessive use of electric motor reduces the battery package SOC. It should be notice that actual driving conditions are unpredictable and thus they are far from what is tested in the standard driving cycles. For these reasons, in this paper are also discussed and presented the results obtained regarding the optimizations of the battery SOC.

Table 4. Simulation results.

\begin{tabular}{|c|c|c|c|c|c|c|c|c|c|c|c|c|}
\hline \multicolumn{13}{|c|}{ Only Diesel Engine } \\
\hline Driving Cycle & \multicolumn{3}{|c|}{ ECE 10} & \multicolumn{3}{|c|}{ ECE 10 - 15} & \multicolumn{3}{|c|}{ UECC } & \multicolumn{3}{|c|}{ NYCC } \\
\hline Distance $[\mathrm{km}]$ & \multicolumn{3}{|c|}{100} & \multicolumn{3}{|c|}{100} & \multicolumn{3}{|c|}{100} & \multicolumn{3}{|c|}{100} \\
\hline Fuel consumption [l/100 km] & \multicolumn{3}{|c|}{2.91} & \multicolumn{3}{|c|}{2.88} & \multicolumn{3}{|c|}{3.00} & \multicolumn{3}{|c|}{3.52} \\
\hline \multicolumn{13}{|c|}{ Vehicle Equipped with the HPP } \\
\hline Driving Cycle & \multicolumn{3}{|c|}{ ECE 10} & \multicolumn{3}{|c|}{ ECE 10 - 15} & \multicolumn{3}{|c|}{ UECC } & \multicolumn{3}{|c|}{ NYCC } \\
\hline Distance $[\mathrm{km}]$ & 50 & 100 & 200 & 50 & 100 & 200 & 50 & 100 & 200 & 50 & 100 & 200 \\
\hline Fuel consumption $[1 / 100 \mathrm{~km}]$ & 2 & 2 & 2 & 2 & 2 & 2.3 & 2.3 & 2.3 & 2.6 & 1.8 & 2.4 & 2.6 \\
\hline State of charge at the end of cycle [\%] & 78 & 60 & 40 & 68 & 47 & $40^{*}$ & 66 & 41 & $54 *$ & 46 & $50 *$ & $43 *$ \\
\hline Endurance before the first alert condition $[\mathrm{km}]$ & & 245 & & & 136 & & & 121 & & & 66 & \\
\hline $\begin{array}{l}\text { Start and stop saving in respect to } \\
\text { the Diesel only configuration [\%] }\end{array}$ & & 10 & & & 10 & & & 12 & & & 18 & \\
\hline $\begin{array}{l}\text { Fuel consumption reduction in respect to } \\
\text { the Diesel only configuration [\%] }\end{array}$ & 31 & 31 & 31 & 31 & 31 & 22 & 24 & 24 & 14 & 48 & 32 & 27 \\
\hline \multicolumn{13}{|c|}{ Only Electric Motor } \\
\hline Driving Cycle & \multicolumn{3}{|c|}{ ECE 10} & \multicolumn{3}{|c|}{ ECE 10 - 15} & \multicolumn{3}{|c|}{ Aggressivo } & \multicolumn{3}{|c|}{ NYCC } \\
\hline State of charge $[\%]$ & \multicolumn{3}{|c|}{30} & \multicolumn{3}{|c|}{30} & \multicolumn{3}{|c|}{30} & \multicolumn{3}{|c|}{30} \\
\hline Endurance $[\mathrm{km}]$ & \multicolumn{3}{|c|}{36.0} & \multicolumn{3}{|c|}{29.7} & \multicolumn{3}{|c|}{23.0} & \multicolumn{3}{|c|}{30.0} \\
\hline
\end{tabular}


Table 5. Comparison table.

\begin{tabular}{|c|c|c|c|c|c|c|c|c|c|c|c|c|}
\hline \multicolumn{13}{|c|}{ Fuel Consumption [l/100 km] } \\
\hline & \multicolumn{3}{|c|}{ ECE 10} & \multicolumn{3}{|c|}{ ECE 10 - 15} & \multicolumn{3}{|c|}{ Aggressivo } & \multicolumn{3}{|c|}{ NYCC } \\
\hline & 50 & 100 & 200 & 50 & 100 & 200 & 50 & 100 & 200 & 50 & 100 & 200 \\
\hline Vehicle equipped with HPP & 2 & 2 & 2 & 2 & 2 & 2.3 & 2.3 & 2.3 & 2.6 & 1.9 & 2.4 & 2.6 \\
\hline Diesel only & & 2.91 & & & 2.88 & & & 3.00 & & & 3.52 & \\
\hline Fuel consumption reduction [\%] & 31 & 31 & 31 & 31 & 31 & 22 & 24 & 24 & 14 & 48 & 32 & 27 \\
\hline \multicolumn{13}{|c|}{ Endurance $[\mathrm{km}]$} \\
\hline & \multicolumn{3}{|c|}{ ECE 10} & \multicolumn{3}{|c|}{ ECE 10 - 15} & \multicolumn{3}{|c|}{ Aggressivo } & \multicolumn{3}{|c|}{ NYCC } \\
\hline Vehicle equipped with HPP & \multicolumn{3}{|c|}{245} & \multicolumn{3}{|c|}{136} & \multicolumn{3}{|c|}{121} & \multicolumn{3}{|c|}{66} \\
\hline Electric-only vehicle & \multicolumn{3}{|c|}{36} & \multicolumn{3}{|c|}{29} & \multicolumn{3}{|c|}{23} & \multicolumn{3}{|c|}{30} \\
\hline
\end{tabular}

The idea of the SOC optimization, here presented, consists in creating a function in the simulation model, called "plug-in function", which contains the information regarding the hypothetical use of the vehicle by the user, for example, distance to drive, time, recharge operations, etc. In addition to the "plug-in function", a specific control for the SOC's lower limit has been also implemented. This is to avoid the possibility of consuming the total battery charge and to have the electric motor available only when SOC is over an upper threshold (70\% of SOC). In the graph below, is shown how the SOC control strategy operates for a NYCC of $200 \mathrm{~km}$ in which $45 \%$ of time the ICE engine works alone.

The adopted strategy is:

- Electric traction plus regenerative brake recharge when the SOC decreases (red curve).

- ICE traction plus regenerative brake recharge when the SOC increases.

The blue line in Figure 8 represents the specific ICE fuel consumption. When the battery charge reaches the lower limit, (see the SOC line in red) the fuel consumption increases and this can be seen by the increase in the slope of the blue line. The fuel consumption increases because the vehicle operates without using the electric motor (too low battery state of charge), and it is affected by the additional weight caused by the unused electric power train.

The "plug-in function" consists of an extra control function added to the control unit in the software model. With this function, it is possible to control and fix, directly by the user, the percentage of electric traction usage. The vehicle user can set the approximate duration of his car trip, i.e. the km driven before recharging the battery. The control unit, thanks to the "plug-in function" and to the knowledge of car's operational conditions, can manage in the "quasi-optimal" way the power delivered by the two motors.

If the car is used for short trips, and frequent recharges are foreseen, the control unit will activate only the electric motor, if possible, or allow its functioning for most of the mission time. If a long trip is scheduled and the battery recharge will not be possible within a short time, then the control unit makes the car work mainly with the ICE engine, thus to avoid the reaching of the battery SOC.

To simulate different conditions to apply different strategies of powering, a gain control was introduced. By increasing the gain value $(>1)$, the control unit will activate the electric motor for most of the time. Decreasing the gain value $(<1)$, the control unit will instead activate the ICE traction. The gain value set in the "plug-in function" is, at the end, an evaluation of the distance to drive and the importance that must be given to the electric traction. In Table 6, are summarized the results of the simulation carried out considering some gain values.

Those specific values have been obtained after several simulations with different driving cycles.

According to the simulation results it can be noted that the adoption of the "plug in" function leads to better results in terms of fuel consumption. The NYCC, because of its nature, it is a very challenging cycle and the optimization offered by the "plug in" function is very effective. The adoption of the "plug-in function" with the gain control reduces the total vehicle consumptions, but the value of the reduction is related to the length of the driving cycle tested. The best gain values found for the different distances tested of the NYCC are reported in 
Table 6. Comparison between the only Diesel configuration vehicle, the Diesel + HPP (HEV) and the HEV plus the "plug in function", obtained with the NYCC.

\begin{tabular}{|c|c|c|c|}
\hline & \multicolumn{3}{|c|}{ DIESEL } \\
\hline Distance (km) & \multicolumn{3}{|c|}{100} \\
\hline Fuel consumption (l/100 km) & \multicolumn{3}{|c|}{3.5} \\
\hline & \multicolumn{3}{|c|}{ HEV } \\
\hline Distance (km) & 50 & 100 & 200 \\
\hline Fuel consumption $(\mathbf{l} / \mathbf{1 0 0} \mathbf{k m})$ & 1.82 & 2.39 & 2.57 \\
\hline State of Charge at the end of the cycle $(\%)$ & 46 & $50^{*}$ & $43 *$ \\
\hline Endurance before discharge (km) & 66 & 66 & 66 \\
\hline \multirow[t]{2}{*}{ Fuel consumption reduction compared with Diesel model (\%) } & 48 & 32 & 27 \\
\hline & \multicolumn{3}{|c|}{ HEV Whit Plug-In Function } \\
\hline Gain ("plug-in function") & 1.8 & 0.4 & 0.25 \\
\hline Distance (km) & 50 & 100 & 200 \\
\hline Fuel consumption (l/100 km) & 1.73 & 2.00 & 2.10 \\
\hline State of charge at the end of the cycle $(\%)$ & $90-37$ & $90-30$ & $90-30$ \\
\hline Endurance before discharge (km) & 55 & 98 & 201 \\
\hline Fuel consumption reduction compared with Diesel model (\%) & 51 & 48 & 41 \\
\hline
\end{tabular}
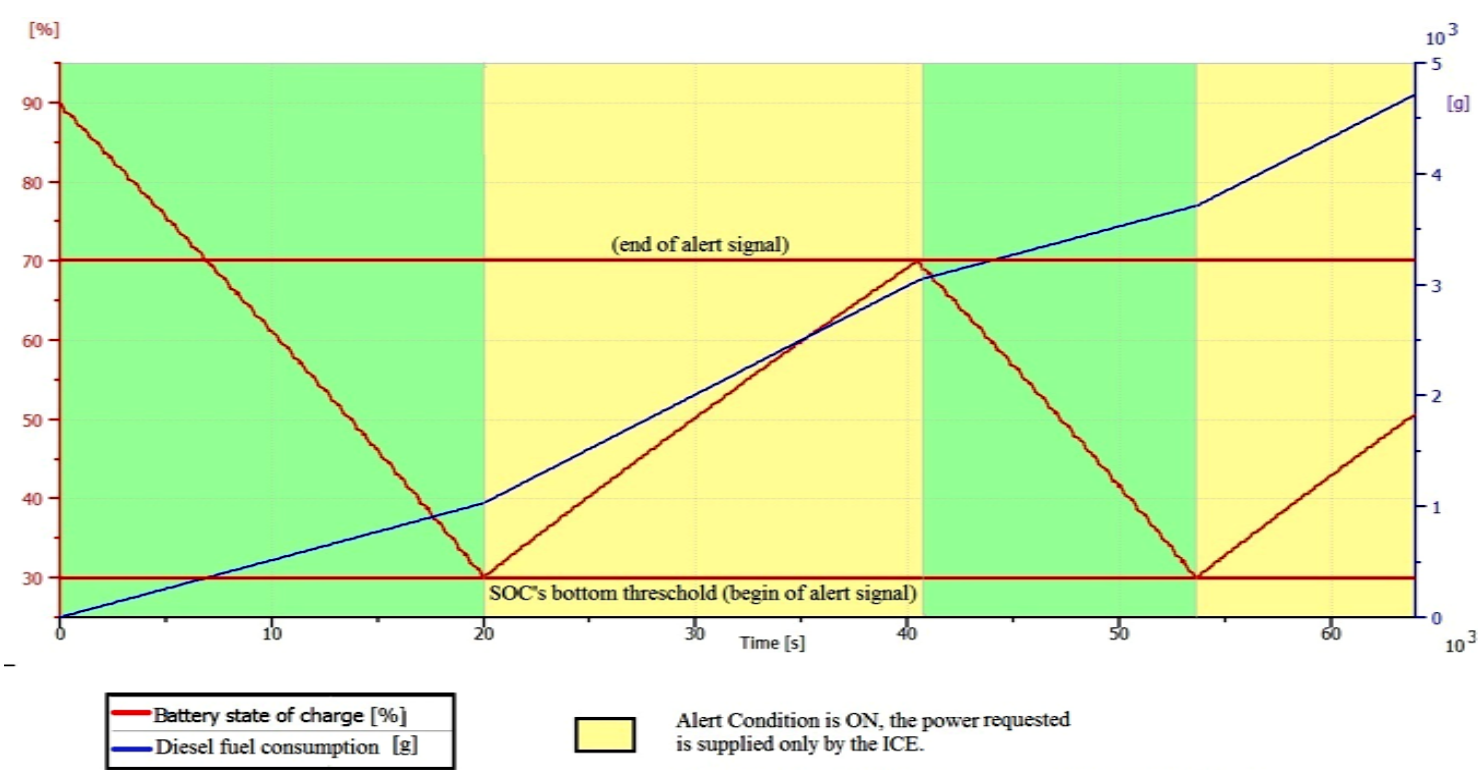

Alert Condition is ON, the power requested is supplied only by the ICE.

Alert Condition in OFF, the power requested is supplied by both motors, according to the control strategy

Figure 8. Trend of the ICE fuel consumption and the battery SOC for a $200 \mathrm{~km} \mathrm{NYCC.}$

the previous table together with the reduction $(\%)$ of fuel consumption obtained in comparison with IEC diesel traction only.

\section{Conclusions}

A hybrid system, mounted on a microcar, must guarantee a minimum reduction in fuel consumption, at least 
$20 \%$ (considering a mild driving cycle) to certificate that the product presented is a valid solution for auto-traction in urban traffic. The HPP presented in this paper obtains a reduction in fuel consumption higher than $20 \%$.

The physical connection between the two motors constitutes a parallel hybrid system. The core of this power pack is the PC-104 unit which controls the strategy of interaction of the ICE and the electric motor. The way that the two motors are managed determines the effective hybrid traction.

For this reason, most of the work presented concentrates on the optimization of the software that controls control unit.

The followings are considerations obtained after having analyzed the results gathered from the simulations (different configurations and different driving cycles):

- The Start \& Stop controller gives a greater reduction in fuel consumption.

- The regenerative brake battery recharge strategy is absolutely necessary and it is used during almost every vehicle deceleration according to the regenerative braking strategy. When the battery SOC falls below $30 \%$, a "security mode" is activated which consists of only diesel ICE traction with regenerative brake battery recharge until SOC reaches $70 \%$.

- The maximum energy recovered by the regenerative brake battery recharge system is limited to the maximum value of the current that can be absorbed by the battery pack system without causing damage. The battery supplier guarantees $30 \mathrm{~A}$ as the maximum recharge current.

- The possibility of recharging the battery pack by "opportunist recharge" has been rejected in this work because recharging the battery utilizing the current produced on board by the ICE engine is too difficult to control and it could possibly cause damaged and/or stress to the storage system.

- The results of the simulations highlight that the performance of the HPP solution presented is comparable with the already existing hybrid vehicles in terms of maximum acceleration, speed and climbing slope.

The solution presented with the HPP with its management strategy and the addition of the "plug-in function"

makes the hybrid vehicle suitable in terms of performance and consumption in every driving condition. The ideal strategy behind the "plug-in function" could represent a guideline for further achievements and experimentations, because it offers a simple hardware layout and a real reduction in fuel consumption.

The future development of the research will be listed as follows:

- Creating a Simulink model based on the Amesim experimental data obtained with the simulations presented in this paper, and installing it in the control unit to test it in an actual prototype.

- Designing a hybrid system that doesn't need to be recharged by plug-in to a charging station, but rather can completely recharge its battery on board using complementary methods.

- Validating the simulation results realizing a real prototype of the vehicle following the scheme modeled in Amesim software and testing it on a dynamometer.

\section{References}

[1] EPA (2013) Testing and Measuring Emissions. [Online] http://www.epa.gov/nvfel/testing/dynamometer.htm

[2] Martellucci, L. and Santoro, M. (2003) Parallel Hybrid Electric Vehicle with Ultracapacitor Energy Storage Tank. The 20th International Electric Fuel Cell and Hybrid Vehicle Symposium, Long Beach, 17 September 2003.

[3] Martellucci, L. (2007) Auxiliary Power Unit Design for an Hybrid Propulsion System with Ultracapacitor Storage System, SAE ICE 07, Capri, Italy. http://dx.doi.org/10.4271/2007-24-0075

[4] Martellucci, L., Di Giacomo, V., Rossi, E. and Sgreccia, S. (2009) Urb-E: ENEA Project for a Low Consumption Urban Vehicle, EVS24 Congress, Stavanger, 14 March 2009.

[5] Badin, F., Briat, O., Olivier, S., Jeanneret, B., Trigui, R. and Malaquin, B. (2004) The Use of Batteries in Hybrid Vehicles. IEEE VPP 2004-Intemational Symposium on Vehicular Power and Propulsion, Paris, 6-8 October 2004.

[6] Affanni, A., Bellini, A., Franceschini, G., Guglielmi, P. and Tassoni, C. (2005) Battery Choice and Management for New Generation Electric Vehicles. IEEE Transactions on Industrial Electronics, 52, 1343-1349.

[7] He, H.-W., Xiong, R. and Chang, Y.-H. (2010) Dynamic Modeling and Simulation on a Hybrid Power System for Electric Vehicle Applications. Energies, 3, 1821-1830.

[8] Hu, X.S., Sun, F.C. and Zou, Y. (2010) Estimation of State of Charge of a Lithium-Ion Battery Pack for Electric Vehicles Using an Adaptive Luenberger Observer. Energies, 3, 1586-1603. http://dx.doi.org/10.3390/en3091586

[9] Wu, J., Li, K., Jiang, Y.F., Lv, Q., Shang, L. and Sun, Y.H. (2011) Large-Scale Battery System Development and User-Specific Driving Behavior Analysis for Emerging Electric-Drive Vehicles. Energies, 4, 758-779. http://dx.doi.org/10.3390/en4050758 
[10] Soga, M., Shimada, M., Sakamoto, J. and Otomo, A. (2002) Development of Vehicle Dynamics Management System for Hybrid Vehicles. JSAE Review, 23, 459-464. http://dx.doi.org/10.1016/S0389-4304(02)00226-6

[11] Barlow, T.J., Latham, S., McCrae, I.S. and Boulter, P.G. (2009) A Reference Book of Driving Cycles for Use in the Measurement of Road Vehicle Emissions. PPR 354, TRL limited.

\section{Nomenclature}

BMS Battery Management System;

BSFC Brake specific fuel consumption;

C Current [A];

CVT Continuously Variable Transmission;

ECE European Cycle;

ECU Electronic Control Unit;

ENEA National Agency for Energy and Environment;

UECC UDR1/ENEA Custom Cycle;

EV Electric Vehicle;

HEV Hybrid Electric Vehicle;

HPP Hybrid Power Pack;

ICE Internal Combustion Engine;

NEDC New European Driving Cycle;

RPM Revolutions per Minute;

SOC State of Charge;

UDR University of Roma;

V Voltage [V]. 
Scientific Research Publishing (SCIRP) is one of the largest Open Access journal publishers. It is currently publishing more than 200 open access, online, peer-reviewed journals covering a wide range of academic disciplines. SCIRP serves the worldwide academic communities and contributes to the progress and application of science with its publication.

Other selected journals from SCIRP are listed as below. Submit your manuscript to us via either submit@scirp.org or Online Submission Portal.
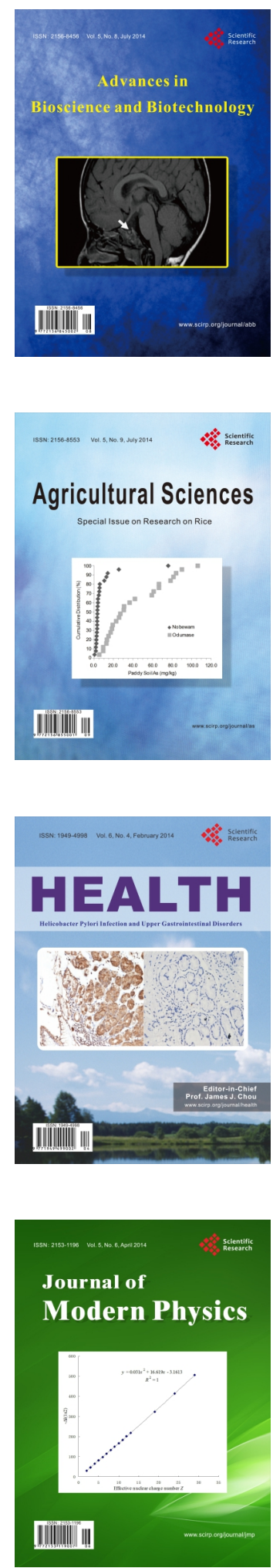
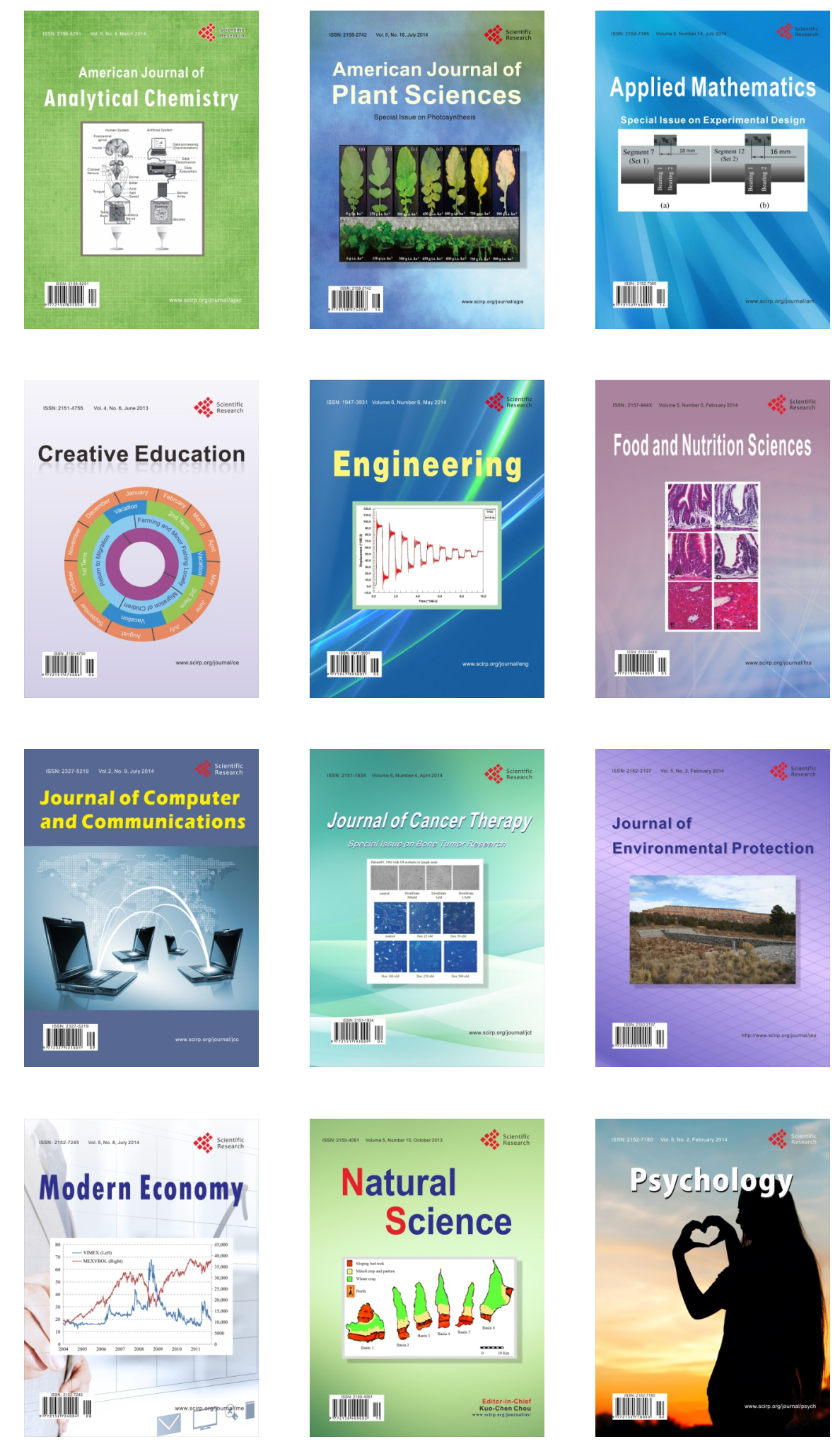